\title{
Identifikasi Waste pada Waktu Tunggu Pasien Rumah Sakit Nasional Diponegoro dengan Pendekatan Lean Hospital
}

\author{
Jessica Christanti Pualamsyah*, Sudiro** \\ *Rumah Sakit Siloam Semarang, ** Fakultas Kesehatan Masyarakat Universitas Diponegoro
}

Email:jessicachristanti@gmail.com

\begin{abstract}
Outpatient waiting time based on minimum standart of care is defined as a time duration since patient in registrated until they meet the doctor. Lean management is a method that could improve outpatient process. There was persistence complain in outpatient waiting time in Diponegoro National Hospital since May 2016 until November 2016. Therefore, lean is expected to improve outpatient wait time. Based on Lean theory, waste is comprised of waste defect, overproduction, transportation, waiting, inventory, motion, overprocessing, and non-utilized talent. This study is going to identified waste that occurred in internal medicine outpatient.
\end{abstract}

This was qualitative study research and conducted by observation, indepth interview, and focussed group disscusion. Total of key informant was 10 internal medicine patients and 6 hospital staffs, including registration, administration, information technology (IT), procurement, helper, and nurse. Total of informant triangulation was 2 informants, including head of outpatient unit and medical records unit. Waste identification was done by value stream mapping analysis and value-added assessment. Root cause analysis (RCA) which used in this study was 5 whys method.

The longest activity in outpatient was waiting in registration booth with mean value of 30,9 minutes, the second was waiting for doctor activity with mean value of 25,2 minutes and the third was waiting medical records to be given by helper with mean value of 8,8 minutes. Waste waiting, overprocessing, defect, inventory, motion were found in this study. It recommends an establisment of flowchart for patient, interdepartment coordination, and Standar Operation Procedure (SOP). Procrument for medical record facility and implementation of $6 S$ culture are mandatory.

Keywords: Lean; Outpatient; Patient Wait Time

\section{PENDAHULUAN}

Waktu tunggu pasien poliklinik berdasarkan Standar Pelayanan Minimal didefinisikan sebagai durasi waktu saat pasien mendaftar di pendaftaran hingga pasien bertemu dengan dokter spesialis. ${ }^{1}$ Peraturan Menkes nomor: 129/menkes/SK/II/2008 tentang Standar Pelayanan Minimal di Instalasi Rawat Jalan menyebutkan bahwa standar ideal waktu tunggu pasien rawat jalan selama $\leq$ 60 menit. $^{1}$ Waktu tunggu yang lama merupakan salah satu faktor ketidakpuasan pasien terhadap rumah sakit di banyak 
negara. $^{2-5}$

Perbaikan kualitas (Quality improvement) yang terencana dan alur pasien yang jelas merupakan hal penting guna optimalisasi dan efisiensi pelayanan pasien. ${ }^{6-7}$ Salah satu metode yang dapat digunakan untuk memperbaiki proses pelayanan dan berorientasi pada nilai pasien adalah mengimplementasikan konsep Lean dalam pelayanan rumah sakit. $^{8-12}$

Tujuan Lean Hospital dalam sistem operasional rumah sakit adalah untuk mengeliminasi waste dan memperbaiki proses pelayanan. Rumah Sakit Nasional Diponegoro (RSND) mengalami persistensi keluhan waktu tunggu di bagian pendaftaran poliklinik sejak bulan Mei 2016 hingga November 2016. Dinesh dan kolega mengimplementasikan Lean pada instalasi rawat jalan menunjukkan adanya penurunan waktu tunggu yang signifikan. ${ }^{11}$ Fenomena serupa juga terjadi pada 2 penelitian di Departemen Ginekologi dan Bedah Urologi Amerika Serikat yang mendapatkan penurunan waktu tunggu yang signifikan. ${ }^{12-13}$

Berdasarkan teori Lean, waste terdiri dari waste defect, overproduction, transportation, waiting, inventory, motion, overprocessing, dan non-utilized talent. ${ }^{3}$ Melalui penelitian ini, metode Lean diharapkan memperbaiki proses rawat jalan di Poliklinik Penyakit Dalam RSND dengan jumlah pasien terbanyak. Penelitian ini bertujuan mengidentifikasi waste yang terjadi di poliklinik penyakit dalam.

\section{METODE PENELITIAN}

Rancangan kualitatif yang disajikan secara deskriptif eksploratif melalui observasi, wawancara mendalam, dan
Focussed Group Disscusion. Penelitian dilaksanakan pada bulan Mei tahun 2017 yang berlokasi di Poliklinik Penyakit Dalam Rumah Sakit Nasional Diponegoro Semarang. Jumlah informan utama terdiri dari 10 pasien penyakit dalam dan 6 petugas rumah sakit yang terdiri dari petugas rekam medis, petugas pendaftaran, petugas administrasi, helper, perawat, petugas IT, petugas bagian pengadaan. Jumlah informan triangulasi terdiri dari 2 informan, yaitu kepala instalasi rawat jalan dan kepala instalasi rekam medik. Metode sampling yang digunakan untuk petugas rumah sakit adalah purposive sampling.

Metode sampling yang digunakan untuk pasien adalah accidental sampling. Pengumpulan data dengan cara wawancara mendalam (indept interview), Focused Group Disscusion, dan observasi. Analisa penelitian ini menggunakan tahapan dalam lean hospital yaitu menentukan current state value stream mapping (CSVSM), eliminasi waste, menstandarisasi proses baru dengan future state value stream mapping(FSVSM). Metode Root Cause Analysis yang digunakan untuk mencari akar permasalahan dalam penelitian ini adalah 5 Whys.

\section{HASIL DAN PEMBAHASAN}

Berdasarkan hasil observasi terhadap proses waktu tunggu pasien poliklinik penyakit dalam, rata-rata waktu yang dihabiskan pasien poliklinik sebesar 65.1 menit. Waktu terlama pertama terjadi pada aktivitas menunggu antrian loket pendaftaran sebesar 30.9 menit. Waktu terlama kedua terjadi pada aktivitas menunggu antrian dokter spesialis sebesar 25.2 menit. Waktu terlama ketiga terjadi pada aktivitas penyerahan rekam medis ke perawat sebesar 8.8 menit. Rasio non value 
added activity dibanding total aktifitas adalah 3 : 7 . Atau sebesar $42.85 \%$. Disimpulkan bahwa proses waktu tunggu pasien poliklinik di Rumah Sakit Nasional Diponegoro belum dalam kondisi lean. Organisasi dikatakan sudah lean apabila rasion antara waste dengan total aktivitas minimum telah mencapai 30\%. (Gazper, 2007). Observasi proses waktu tunggu rawat jalan oleh peneliti menghasikan
Current State Value Stream Mapping Poliklinik Penyakit Dalam dijabarkan pada gambar 1.

\section{Identifikasi Waste Pada Proses Waktu Tunggu Poliklinik Penyakit Dalam}

Waste yang ditemukan dalam observasi dan wawancara dijabarkan pada tabel 1 .

Tabel 1. Temuan Waste proses waktu tunggu pasien poliklinik

\begin{tabular}{|c|c|c|c|}
\hline No. & $\begin{array}{l}\text { Kondisi } \\
\text { temuan }\end{array}$ & Jenis Waste & Contoh temuan di Rumah Sakit \\
\hline 1. & Observasi & $\begin{array}{l}\text { Waiting } \\
\text { Motion } \\
\text { Overprocessing }\end{array}$ & $\begin{array}{l}\text { Pasien menunggu antrian loket pendaftaran. } \\
\text { Mencari dokumen rekam medis ke berbagai } \\
\text { tempat. } \\
\text { Pencatatan identitas pasien dilakukan } \\
\text { berulang-ulang. Pencatatan identitas pasien } \\
\text { dilakukan berulang-ulang pada lembar } \\
\text { pengantar pemeriksaan penunjang, kertas } \\
\text { resep, dan surat kontrol. }\end{array}$ \\
\hline 2. & Wawancara & $\begin{array}{l}\text { Unnecessary } \\
\text { Inventory } \\
\text { Defect }\end{array}$ & $\begin{array}{l}\text { Pembuatan rekam medis baru untuk pasien } \\
\text { yang rekam medisnya tidak ditemukan oleh } \\
\text { helper. } \\
\text { Helper mengambil rekam medis tanpa alat } \\
\text { bantu seperti tangga sehingga petugas harus } \\
\text { memanjat lemari. Meja perawat di poli } \\
\text { penyakit dalam tidak ergonomis karena } \\
\text { sebenarnya meja tersebut hanya berfungsi } \\
\text { sebagai lemari kaca saja. } \\
\text { Dokter yang terlambat datang dapat } \\
\text { memperlama waktu tunggu antrian pasien } \\
\text { poliklinik.Perawat menunggu helper untuk } \\
\text { diambilkan rekam medis pasien. }\end{array}$ \\
\hline
\end{tabular}




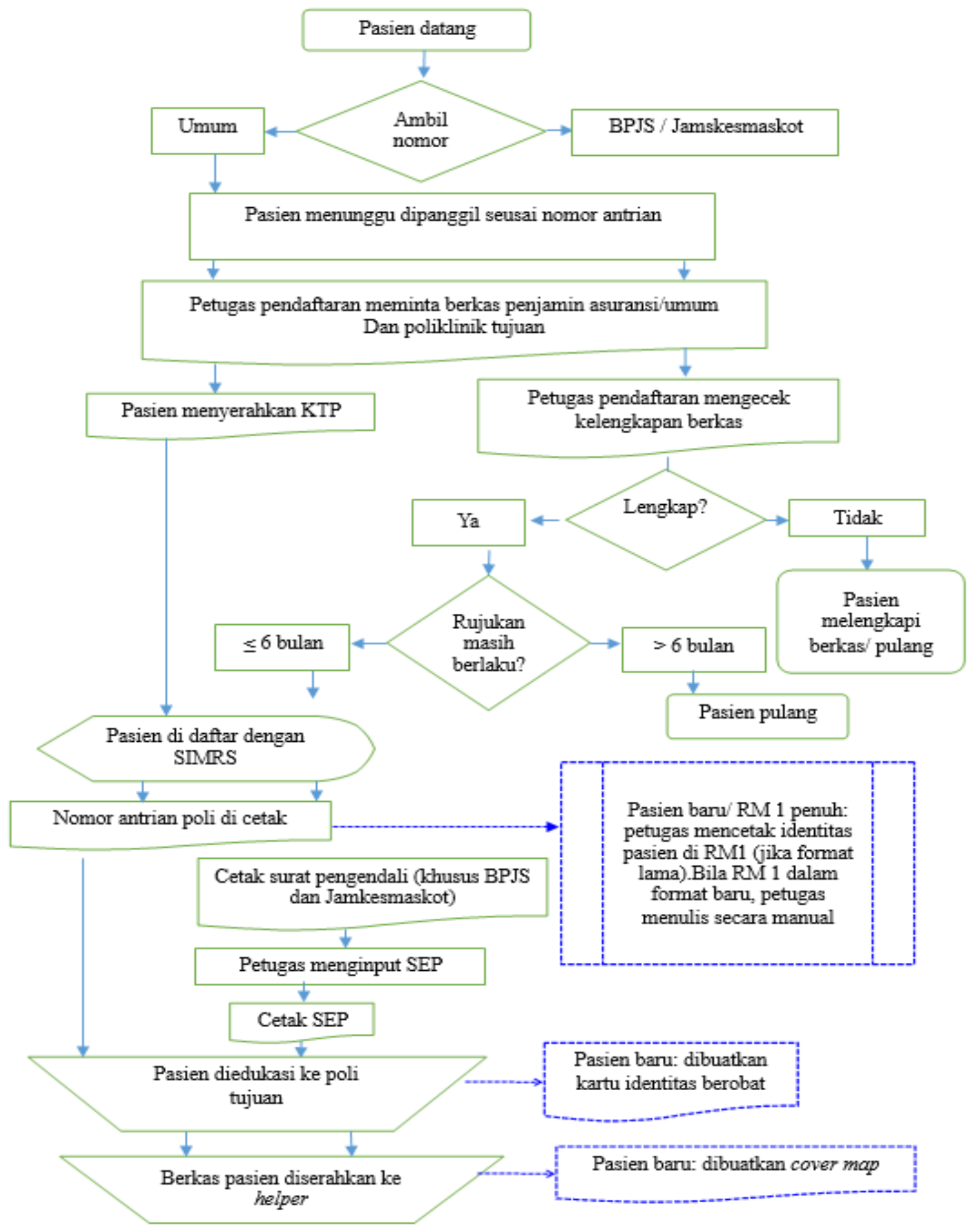

Gambar 1. Current State Value Stream Mapping Poliklinik Penyakit Dalam 


\section{Root Cause Analisis (RCA)}

Hasil diskusi melalui FGD yang dilakukan oleh fasilitator FGD terhadap 8 petugas instalasi rawat jalan untuk mencari akar permasalahan waste dengan metode five whys. ${ }^{14}$

Waste Motion terhadap aktivitas petugas rumah sakit disebabkan karena belum adanya regulasi yang mengatur kepatuhan helper terhadap prosedur pengambilan rekam medis, minimnya pengetahuan petugas terkait standar prosedur operasional (SPO) alur pengadaan barang seperti tangga, sosialisasi SPO alur pengadaan terbaru belum dilakukan oleh direktur, dan regulasi yang mengatur koordinasi antar bagian guna pengembangan kebutuhan rumah sakit seperti pembaharuan sistem informasi rumah sakit (SIMRS) untuk rekam medis belum ada.

Waste Waiting yang terjadi baik pada petugas rumah sakit dan pasien disebabkan karena regulasi yang mengatur koordinasi antar bagian guna pengembangan kebutuhan seperti diskusi antar bagian untuk eliminasi prosedur rumah sakit, pembaharuan SIRMS (meliputi, sistem cetak lembar rekam medis 1, integrasi surat eligibilitas peserta dengan surat pengendali, informasi posisi rekam medis) belum ada sehingga perawat akhirnya menunggu rekam medis dari helper. Minimnya pengetahuan petugas terkait standar prosedur operasional (SPO) alur pengadaan barang seperti mesin cetak kartu identitas berobat (KIB) dan sosialisasi SPO alur pengadaan terbaru belum dilakukan oleh direktur sehingga menimbulkan waste waiting.

Beberapa dokter datang terlambat saat proses waktu tunggu rawat jalan berlangsung sehingga waktu tunggu pasien memanjang (waste waiting) yang disebabkan karena reward dan recognition terhadap prosedur pelayanan belum ada.

Waste Overprocessing yang terjadi pada petugas rumah sakit disebabkan karena belum ada regulasi yang mengatur koordinasi antar bagian untuk pengembangan rumah sakit seperti pengadaan dot printing untuk mencetak identitas pasien, pembaharuan SIMRS untuk pencetakan identitas pasien, dan penataan ulang ruang poliklinik. Minimnya pemahaman SPO alur pengadaan barang menyebabkan waste overprocessing terjadi karena tidak ada upaya untuk mempercepat proses pelayanan.

Waste Unnecessary Inventory seperti pembuatan rekam medis baru bila rekam medis lama tidak ditemukan dan waste defect seperti petugas memanjat lemari fulling untuk mengambil rekam medis tersebut timbul dengan penyebab yang sama seperti waste motion.

\section{Usulan Perbaikan Proses Waktu Tunggu Pasien Poliklinik Penyakit Dalam.}

Analisa 5 Why telah dilakukan pada aktivitas loket pendaftaran dijabarkan pada tabel 2 . 
Tabel 2 . Usulan perbaikan aktivitas loket pendaftaran.

\begin{tabular}{|c|c|c|}
\hline Masalah & Akar Masalah & Usulan Perb \\
\hline $\begin{array}{l}\text { Sistem pencetakan identitas } \\
\text { pasien pada RM1 format } \\
\text { lama tidak diikuti dengan RM } \\
1 \text { format baru sehingga } \\
\text { penulisan identitas pasien } \\
\text { masih ditulis dengan tangan. }\end{array}$ & $\begin{array}{l}\text { Regulasi yang } \\
\text { mengatur koordinasi } \\
\text { antar bagian guna } \\
\text { pengembangan } \\
\text { kebutuhan rumah } \\
\text { sakit belum ada. }\end{array}$ & $\begin{array}{l}\text { Pembentukan sistem flwochart dan } \\
\text { sosialisasi terkait koordinasi antar } \\
\text { bagian (rekam medis dan IT) } \\
\text { diperlukan guna pengembangan } \\
\text { rumah sakit. Evaluasi setelah } \\
\text { implementasi regulasi perlu } \\
\text { dilakukan agar dapat menyelesaikan } \\
\text { hambatan yang terjadi. }\end{array}$ \\
\hline $\begin{array}{l}\text { Pencetakan SEP dan surat } \\
\text { pengendali dicetak secara } \\
\text { terpisah sehingga petugas } \\
\text { mengerjakan hal yang sama } \\
\text { berulang kali dan } \\
\text { memperlama proses waktu } \\
\text { tunggu di loket pendaftaran } \\
\text { untuk pemanggilan pasien } \\
\text { selanjutnya. }\end{array}$ & $\begin{array}{l}\text { Regulasi yang } \\
\text { mengatur koordinasi } \\
\text { antar bagian guna } \\
\text { pengembangan } \\
\text { kebutuhan rumah } \\
\text { sakit belum ada. }\end{array}$ & $\begin{array}{l}\text { Pembentukan SPO Alur pengadaan } \\
\text { dan koordinasi antar bagian dalam } \\
\text { flowchart serta pihak yang } \\
\text { bertanggung jawab pada tahap } \\
\text { tersebut. Sosialisasi dan pengesahan } \\
\text { SPO perlu dilakukan. }\end{array}$ \\
\hline $\begin{array}{l}\text { Kurangnya bahan pembuat } \\
\text { kartu identitas berobat (KIB) } \\
\text { dan alat pencetak kartu maka } \\
\text { KIB dibuat dengan tulisan } \\
\text { tangan sehingga memperlama } \\
\text { proses waktu tunggu di loket } \\
\text { pendaftaran untuk } \\
\text { pemanggilan } \\
\text { selanjutnya. }\end{array}$ & $\begin{array}{lr}\text { Pengesahan } & \text { dan } \\
\text { sosialisasi } & \text { SPO alur } \\
\text { pengadaan } & \text { terbaru } \\
\text { belum dilakukan oleh } \\
\text { direktur sehingga } \\
\text { pengusulan alat dan } \\
\text { bahan terhambat } \\
\text { karena petugas saling } \\
\text { merasa rakan } \\
\text { wewenangnya. }\end{array}$ & $\begin{array}{l}\text { a. Bagian rekam medis dan bagian } \\
\text { IT perlu mengadakan koordinasi } \\
\text { pengadaan printer kartu berobat } \\
\text { RS. } \\
\text { b. Pembentukan SPO Alur } \\
\text { pengadaan dan koordinasi antar } \\
\text { bagian dalam flowchart serta } \\
\text { pihak yang bertanggung jawab } \\
\text { pada tahap tersebut. Sosialisasi } \\
\text { dan pengesahan SPO perlu } \\
\text { dilakukan. }\end{array}$ \\
\hline
\end{tabular}

Temuan ini serupa dengan penelitian yang dilakukan oleh Dinesh et al pada tahun 2013 di India, bahwa minimnya fasilitas yang mendukung kerja dapat menghambat suatu proses untuk bergerak lebih cepat dan tepat. Koordinasi yang minim antar bagian dan ketidaktahuan terkait peraturan yang berlaku di Rumah sakit juga menjadi faktor penghambat proses waktu tunggu rawat jalan ${ }^{11}$.
Penelitian oleh Ho et al pada tahun 2014 di Singapura menyatakan bahwa kualitas pelayanan tidak hanya terfokus pada kemampuan klinis dokter dan perawat tetapi lingkungan kerja, alur kerja, dan komunikasi juga mempengaruhi kualitas pelayanan. Adaptasi suatu solusi pelayanan rawat jalan menjadi bagian dari regulasi rumah sakit menjadi penyebab keberhasilan suatu intervensi. ${ }^{15}$ Usulan perbaikan untuk pelayanan rawat jalan di 
loket pendaftaran seperti pembentukan regulasi dan sosialisasi terkait koordinasi antar bagian (rekam medis dan IT) diperlukan untuk pengembangan rumah sakit dan komunikasi antar bagian terjalin secara sistematis. Evaluasi setelah implementasi regulasi perlu dilakukan agar dapat menyelesaikan hambatann yang terjadi.

Berdasarkan observasi pada proses waktu tunggu pasien poliklinik penyakit dalam, proses terlama kedua yang terjadi pada antrian pasien menunggu pemeriksaan dokter. Pada proses tersebut dokter spesialis yang praktek datang pada pk 08.00 (tepat waktu), akan tetapi ratarata waktu tunggunya berkisar 25.2 menit. Hal tersebut bisa dikarenakan memang proses pemeriksaan yang harus dijalani oleh pasien. Analisa 5 Why telah dilakukan pada aktivitas antrian poliklinik dijabarkan pada tabel 3 .

Tabel 3. Usulan perbaikan aktivitas antrian poliklinik.

\begin{tabular}{|c|c|c|}
\hline Sumber Masalah & Akar Masalah & Usulan Perbaikan \\
\hline $\begin{array}{l}\text { Dokter terlambat datang } \\
\text { sehingga memperlama waktu } \\
\text { menunggu pasien saat } \\
\text { mengantri pemeriksaan } \\
\text { dokter. Hal ini dapat } \\
\text { memperpanjang } \text { waktu } \\
\text { tunggu pasien dengan antrian } \\
\text { selanjutnya. }\end{array}$ & $\begin{array}{lr}\text { Regulasi } & \text { terkait } \\
\text { reward } & \text { dan } \\
\text { recognition } & \\
\text { terhadap prosedur } \\
\text { pelayanan belum } \\
\text { ada. }\end{array}$ & $\begin{array}{l}\text { Perlu koordinasi } \text { (pemaparan, } \\
\text { himbauan, solusi penjadwalan aktivitas } \\
\text { dokter spesialis) dengan para dokter } \\
\text { spesialis disertai temuan data } \\
\text { dilapangan terkait waktu tunggu dan } \\
\text { kepuasan pasien. } \\
\text { Membuat regulasi terkait reward dan } \\
\text { recognition terhadap prosedur } \\
\text { pelayanan. }\end{array}$ \\
\hline
\end{tabular}

Penelitian Gijo et al pada tahun 2013 di India menyatakan bahwa keterlambatan dokter juga merupakan faktor yang memperlama proses waktu tunggu, temuan serupa terjadi di RSND dimana ada beberapa dokter yang datang terlambat. ${ }^{16}$ Pada penelitian Gijo, alasan dokter tersebut terlambat disebabkan karena dokter melakukan visite bangsal kemudian melayani pasien rawat jalan dan solusi disebutkan pengaturan jadwal ulang dengan memprioritaskan pelayanan rawat jalan dilakukan pada penelitian tersebut ${ }^{16}$.

Penelitian yang dilakukan oleh Mosadeghrad pada tahun 2014 menunjukan bahwa sistem reward dan recognition yang diimplementasikan pada pegawai rumah sakit akan meningkatkan kepuasan pegawai sehingga petugas bekerja lebih baik dan meningkatkan kepuasan pasien. ${ }^{17}$ Oleh karena itu usulan perbaikan terkait keterlambatan dokter di rawat jalan bisa dilakukan dengan menetapkan regulasi reward dan recognition serta penjadwalan ulang aktivitas dokter.

Berdasarkan observasi proses waktu tunggu pasien poliklinik penyakit dalam , ditemukan proses terlama ketiga adalah rekam medis tiba di perawat. Dalam proses tersebut disebabkan oleh berbagai wast, meliputi waste motion, waste inventory dan waste defect. Waste tersebut dapat memperlambat suatu proses dimana proses tersebut juga memiliki waste lainnya seperti waste overprocessing. Oleh karena 
itu, analisa 5 Why dilakukan untuk usulan perbaikan pada aktivitas petugas rekam medis dan perawat dijabarkan pada tabel
Analisa 5 Why dilakukan untuk usulan perbaikan pada aktivitas petugas rekam medis dan perawat dijabarkan pada tabel 4 .

Tabel 4. Usulan perbaikan aktivitas rekam medis dan perawat

\begin{tabular}{|c|c|c|c|}
\hline Sumber Masalah & & Akar Permasalahan & Usulan Perbaikan \\
\hline $\begin{array}{l}\text { Helper mencari } \\
\text { rekam medis di } \\
\text { berbagai tempat dan } \\
\text { bila rekam medis } \\
\text { ditemukan, maka } \\
\text { helper membuat } \\
\text { rekam medis baru }\end{array}$ & c. & $\begin{array}{l}\text { Belum adanya regulasi } \\
\text { yang mengatur kepatuhan } \\
\text { helper terhadap prosedur } \\
\text { pengambilan rekam } \\
\text { medis. } \\
\text { Minimnya pengetahuan } \\
\text { petugas terkait SPO alur } \\
\text { pengadaan barang dan } \\
\text { pengesahan } \\
\text { sosialisasi SPO alur } \\
\text { pengadaan terbaru belum } \\
\text { dilakukan oleh direktur. } \\
\text { Koordinasi antar bagian } \\
\text { guna pengembangan } \\
\text { kebutuhan rumah sakit } \\
\text { belum ada. }\end{array}$ & 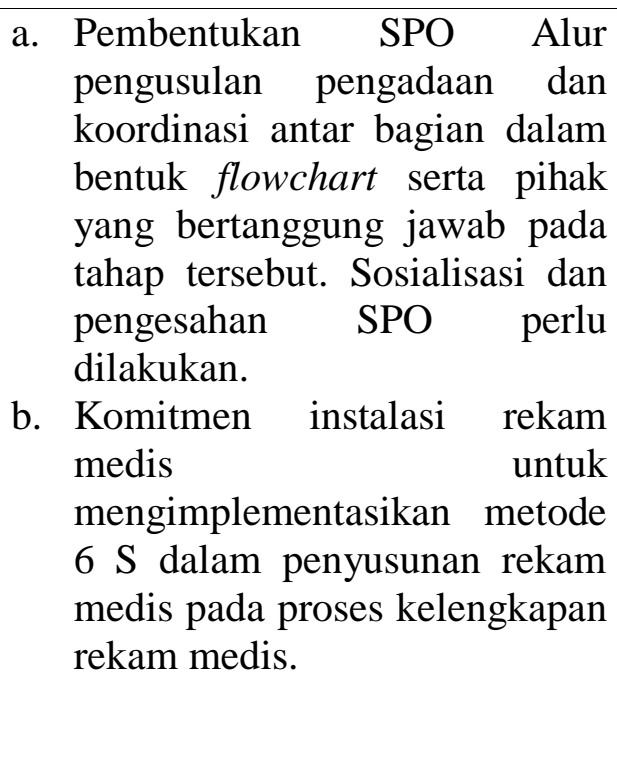 \\
\hline $\begin{array}{l}\text { Perawat menulis } \\
\text { identitas pasien } \\
\text { secara berulang di } \\
\text { surat kontrol, resep } \\
\text { pasien, dan lembar } \\
\text { pemeriksaan } \\
\text { penunjang. }\end{array}$ & a. & $\begin{array}{l}\text { Koordinasi antar bagian } \\
\text { guna pengembangan } \\
\text { kebutuhan rumah sakit } \\
\text { belum ada terutama } \\
\text { terkait permohonan } \\
\text { bantuan } \\
\text { memindahkan barang } \\
\text { besar. } \\
\text { Koordinasi antar bagian } \\
\text { guna pengembangan } \\
\text { kebutuhan rumah sakit } \\
\text { belum ada, koordinasi } \\
\text { antar bagian IT dan } \\
\text { rekam medis masih } \\
\text { kurang, dan pemahaman } \\
\text { SPO alur pengadaan } \\
\text { barang masih kurang. }\end{array}$ & $\begin{array}{l}\text { a. Pemanfaatan meja di ruang } \\
\text { poliklinik penyakit dalam } \\
\text { dengan memindahkan meja. } \\
\text { Penataan dibantu oleh office } \\
\text { boy poliklinik yang bertugas } \\
\text { saat pergantian shift. (skema } \\
\text { dalam gambar 4.9). } \\
\text { b. Koordinasi bagian IT dan } \\
\text { rekam medis terkait prioritas } \\
\text { kebutuhan dan pengadaan } \\
\text { printer dot matrik. } \\
\text { c. Pembentukan SPO Alur } \\
\text { pengadaan dan koordinasi antar } \\
\text { bagian dalam flowchart serta } \\
\text { pihak yang bertanggung jawab } \\
\text { pada tahap tersebut. Sosialisasi } \\
\text { dan pengesahan SPO perlu } \\
\text { dilakukan. }\end{array}$ \\
\hline
\end{tabular}


Temuan ini serupa dengan penelitian yang dilakukan oleh Dinesh et al pada tahun 2013 di India menyatakan bahwa terdapat faktor fasilitas yang mempengaruhi waktu tunggu rawat jalan seperti tidak sempurnanya sistem komputer dan sistem komputer terlalu lama dan faktor manusia seperti minimnya pelatihan dan komunikasi antar bagian ${ }^{11}$. Penelitian oleh Ho et al pada tahun 2014 di Singapura menyatakan bahwa kualitas pelayanan tidak hanya terfokus pada kemampuan klinis dokter dan perawat tetapi lingkungan kerja, alur kerja, dan komunikasi juga mempengaruhi kualitas pelayanan. Adaptsi suatu solusi pelayanan rawat jalan menjadi bagian dari regulasi rumah sakit menjadi penyebab keberhasilan suatu intervensi. $^{15}$ Oleh karena itu, usulan perbaikan untuk pelayanan rawat jalan terutama pada aktivitas helper adalah pemaparan ulang terkait SPO alur pengusulan pengadaan barang sebaiknya tersosialisasikan ke semua petugas rumah sakit dan dibuat atas sepengetahuan direktur, koordinasi antar bagian IT dan rekam medis terkait pembuatan sistem SIMRS rekam medis secara terintegrasi, dan komitmen instalasi rekam medis untuk mengimplementasikan metode $6 \mathrm{~S}$ dalam penyusunan rekam medis pada proses kelengkapan rekam medis.

Usulan untuk aktivitas perawat rawat jalan adalah pemanfaatan meja di ruang poliklinik penyakit dalam dengan memindahkan meja. Penataan dibantu oleh office boy poliklinik yang bertugas saat pergantian shift. (skema dalam lampiran), koordinasi bagian IT dan rekam medis terkait prioritas kebutuhan dan pengadaan printer dot matrik, dan SPO Alur pengusulan pengadaan barang sebaiknya tersosialisasikan ke semua petugas rumah sakit dan dibuat atas sepengetahuan direktur.

\section{KESIMPULAN}

Rata-rata Aktivitas terlama dari proses waktu tunggu pasien poliklinik adalah menunggu di loket pendaftaran (30.9 menit), aktivitas terlama kedua adalah menunggu antrian dokter spesialis (25.2 menit), dan aktivitas terlama ketiga adalah penyerahan rekam medis ke perawat (8.8 menit).

Akar masalah yang mendominasi saat proses waktu tunggu pasien poliklinik penyakit dalam adalah minimnya pengetahuan petugas terkait SPO alur pengadaan barang yang meliputi flowchart alur serta pihak yang bertanggung jawab pada tahap tersebut. Pengesahan dan sosialisasi SPO alur pengadaan oleh direktur belum dilakukan. Flowchart koordinasi antar bagian dan pihak yang bertanggung jawab pada tahap tersebut perlu disusun agar lebih terarah.

Pelaksanaan budaya $6 \mathrm{~S}$ diperlukan di instalasi rekam medik dan instalasi rawat jalan agar meningkatkan kepuasan kerja petugas dan kepuasan pasien.

\section{UCAPAN TERIMA KASIH}

Penulis memberikan ucapan terima kasih kepada Rumah Sakit Nasional Diponegoro atas kesediaannya sebagai institusi tempat penelitian.

\section{DAFTAR PUSTAKA}

1. Depkes, MENTERI KESEHATAN REPUBLIK INDONESIA NOMOR: 129/Menkes/SK/II/2008, Tentang Standar Pelayanan Medis. (Jakarta : Depkes RI. 2008). Departemen Kesehatan RI.

2. Oche MO, Adamu H. Determinants of Patient Waiting Time in the General 
Outpatient Department of a Tertiary Health Institution in North Western Nigeria. Annals of Medical and Health Sciences Research, Oct-Dec 2013, Vol 3.

3. Ishijima Hisahiro et al. The " $5 \mathrm{~S}$ " approach to improve a working environment can reduce waiting time: Findings from hospitals in Northern Tanzania. The TQM Journal Vol. 28 No. 4, 2016.

4. Anderson Roger T, Fabian T Camacho, Rajesh Balkrishnan. Willing to wait?: The influence of patient wait time on satisfaction with primary care. BMC Health Services Research20077:31[4]

5. Marco Catherine A. Et al. The Ethics of Health Care Reform: Impact on Emergency Medicine. Academic Emergency Medicine, volume 19,issue 4, 16 Apr 2012[5]

6. Michael Melanie. Improving Wait Times and Patient Satisfaction in Primary Care. Journal for Healthcare Quality, Volume 35, Issue 2,March/April 2013.[6]

7. Batalden Paul B, Frank Davidoff. What is "quality improvement" and how can it transform healthcare? BMJ Quality\&Safety.2006. Volume 16, Issue $\underline{1}$

8. Tapani Jorma Hanna Tiirinki Risto Bloigu Leena Turkki , (2016),"LEAN thinking in Finnish healthcare", Leadership in Health Services, Vol. 29 Iss 1 pp. $9-36$

9. Yu Ting, et al. A General Framework for Lean Transformation of Hospitals. Conference Paper · March 2015

10. Womack James P, Daniel T. Jones. Lean Thinking Banish Waste and Create Wealth in Your Corporation. Journal of the Operational Research Society . January 1996
11. Dinesh, et al. Reducing Waiting Time In Outpatient Services Of Large University Teaching Hospital - A Six Sigma Approach. MANAGEMENT IN HEALTH, VOL 17, NO 1 (2013)

12. Skeldon, et al. Lean methodology improves efficiency in outpatient academic uro-oncology clinics. Urology. 2014 May;83(5):992-7.

13. Linda, et al. Lean methodology improves efficiency in outpatient academic Gynecologic Oncology clinics. Gynecologic Oncology 138(3) · July 2015.

14. Jucan, G., 2005. Root Cause Analysis for IT Incidents Investigation.. http://www.docstoc.com/docs/16171902/ Root-Cause-Analysis; tanggal 15 Mei 2014

15. Ho Emily Tse Lin. Improving waiting time and operational clinic flow in a tertiary diabetes center. BMJ Qual Improv Rep. 2014; 2(2): u201918.w1006.

16. Ev Gijo,etal. Reducing Patient Waiting Time in Outpatient Department Using Lean Six Sigma Methodology. Qual. Reliab. Engng. Int. 2013

17. Mosadeghrad Ali Mohammad. Strategic collaborative quality management and employee job satisfaction. Int $\mathrm{J}$ Health Policy Manag 2014, 2(4), 167-174. 